International Journal of English Language Studies (IJELS)

ISSN: 2707-7578

DOI: $10.32996 /$ ijels

Website: https://al-kindipublisher.com/index.php/ijels

\title{
Cheating on Exams: Dishonest or Justifiable Behaviour?
}

\author{
Abdelhak Hammoudi ${ }^{1}$ (D) $\triangle$ and Samah Benzerroug ${ }^{2}$ (D) \\ ${ }^{1}$ Teacher Training College El Eulma, Sétif, Algeria \\ ${ }^{2}$ Teacher Training College Bouzareah, Algiers, Algeria \\ $\triangle$ Corresponding Author: Abdelhak Hammoudi, E-mail: hammoudiabdelhak@yahoo.com
}

\begin{tabular}{ll}
\hline ARTICLE INFORMATION ABSTRACT \\
\hline
\end{tabular}

Received: March 04, 2021

Accepted: April 16, 2021

Volume: 3

Issue: 4

DOI: $10.32996 /$ ijels.2021.3.3.7

\section{KEYWORDS}

Cheating on exams

Multiple Intelligences

survival intelligence

justifiable behavior

exams content

exam anxiety
Academic dishonesty has been a perennial issue in higher education for hundreds of years. The advent of technological devices has spurred much more concern regarding the so-called inappropriate use of these tools and their impact on the ethical behaviour of the students. The main aim of this study was to demonstrate to educators that cheating on exams is most of the time a justifiable and smart behaviour. To support this assumption, the study investigated (a) the reasons that often push students to resort to cheating and (b) the role of exam anxiety in engaging students' survival intelligence to respond to examinations threat with whatever the means. The results, based on a sample of one 100 students from the English language department indicate that $90 \%$ of the students think that the way the examinations are designed constitutes the main cause of cheating: questions test memory rather than comprehension. Teachers themselves trigger cheating on exams because the content of their exams does not take into account students' Multiple Intelligences, and preferred channels of learning. Consequently, students' survival intelligence, feeling a threat causing exam anxiety, engages itself and automatically sets the learner to cheat 'without actively thinking about it.' The current results might be applicable to students in other academic disciplines.

\section{Introduction}

Historically, academic dishonesty has been a crucial element in the advance of research and education. However, with the advent of technological devices, cheating has become omnipresent in our classrooms. This academic misbehaviour for most scholars, though considered illogic, immoral, and even sinful for some cultures, has invaded schools and is 'destroying' the ethics of education. Recent estimates indicate that most of students all over the world cheat to some extent and the number of cheaters is rising more and more. In the USA, the cradle of education development and innovation, most universities are suffering from this phenomenon. A CNN investigation (2012) has found that 'for years, doctors round the country taking an exam to become board certified in radiology have cheated by memorising test questions, creating sophisticated banks of what are known as "recalls". In an article titled "Today's kids view cheating as part of the path to success". Dorff (2012) mentioned that "students, parents, teachers and administrators complain that there is too much cheating going on in our schools, but they tend to point at each other when asked who should be responsible for fixing the problem." In UK, the situation is not different at all. According to an investigation by the Independent (2012)"tens of thousands of students in universities across Britain have been caught cheating in exams and coursework - and the trend is on the rise."

Almost everybody has succumbed to the use of inappropriate resources to get high grades in exams. Grades have become the major focus of most students. Verily, cheating has turned a big dilemma and has reached epidemic proportions in our schools. It is not stopping. On the contrary, it is skyrocketing. What is wrong with higher education today? Why do students cheat? How can we remedy?

This article is an attempt to highlight the main causes of this so-called academic misconduct, prove that it is justifiable and suggest some solutions to plummet the exam operation defects.

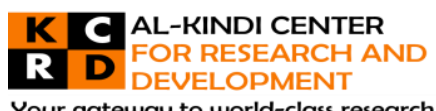

Your gateway to world-class research

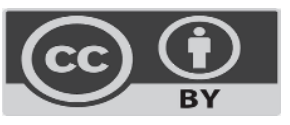

Published by Al-Kindi Center for Research and Development. Copyright (c) the author(s). This open access article is distributed under a Creative Commons Attribution (CC-BY) 4.0 license 


\section{Literature Review - Cheating on Exams: An Overview}

Scholars note that cheating was prevalent thousands of years ago. According to Lang (2013) in ancient China, cheating was considered as a crime and met with the penalty of death for both examinee and examiner. Since the ancient Chinese era up to now, cheating has been developing using different means and methods. No one has been able to stop this behaviour in spite of the great invigilance of educational authorities and testing services.

Most people think that the main cause behind cheating on exams is to avoid failure and to get excellent marks. Others believe cheaters are lazy students who rarely attend lectures and often fail to review their lessons. These beliefs might possess some truth, but not all the truth. Some of the cheating reasons, which appear to us as true and verifiable are as follows (Eberly Center):

- $\quad$ Students might blame their cheating behaviour on unfair/ too difficult tests and/or teachers.

- Some students might feel an obligation to help certain other students succeed on exams-for example, a relative, or club-mate,

- $\quad$ Some students might cheat because they have poor study skills that prevent them from keeping up with the material.

- Students cheat or plagiarise if they have low expectations of success due to perceived lack of ability or exam anxiety.

\subsection{Types of Cheating}

According to academic INTEGRITY (2018), academic dishonesty falls into eight (08) categories:

1. Basic Violations, include : limited unauthorised collaboration; submitting a part of the same material more than once without prior permission; giving one's own academic work to others; possessing smart technology (e.g., cell phone, smart watch) accessible during an exam; violation of class/instructor policies

2. Assignment Misconduct, includes, but is not limited to: looking online for a solution to an assignment and copying that solution/answer; copying a portion of another student's assignment or working extensively with another student on an individual assignment; making one's work available to another student (directly or indirectly) when it was specifically prohibited to do so.

3. Extensive Plagiarism includes but is not limited to: plagiarism when the aspects copied, are critical aspects of the assignment and/or constitute more than $50 \%$ of the assignment; allowing another (e.g. friend/relative/roommate/classmate/tutor) to edit/write/translate one's assignment without acknowledging that help; extensively copying from another student's assignment; limited or extensive plagiarism that includes false citations

4. Exam Cheating includes, but is not limited to: copying from another or allowing another to copy; having an aid directly related to the exam (e.g., "cheat sheets"; course related notes; text book; whether electronically or hard copy); copying or plagiarising on take-home exam

5. Falsification/Fabrication includes, but is not limited to: altering a graded assessment and submitted for re-grade; fabricating data for a lab or research assignment; submitting data you did not yourself collect; lying/giving a false excuse to miss or receive unfair accommodation on an assessment

6. Fraud includes some of the most egregious violations - e.g., stealing or fraudulently obtaining answers to an assessment prompt/exam before submitting the assessment for grading; changing/helping to change any recorded assignment or course grade on an instructor's or university record; illicitly obtaining an assessment completed by another (without their knowledge) and submitting it (in part or whole) as one's own; submitting fake or false documents (e.g., medical notes)

7. Contract Cheating is any behavior by which a student arranges to have another person or entity ("the provider") complete (in part or total) an assessment (e.g., exam, test, quiz, assignment, paper, project, problems) for the student. If the provider is also a student, both students are in violation.

\subsection{Known Ways of Cheating on Exams}

Describing the known ways of cheating is not an aim in itself. It aims at showing how smart are these students' cheating strategies. We used the term 'known ways' because there are many others, classified top secret. Only the cheater knows them.

"10 crazy and inventive ways students have cheated in exams", "45 Genius Cheaters Who Deserve A+ For Their Creativity", "9 Creative and Inventive Ways for Students to Cheat in Exams", are article titles describing ways of cheating on exams. The most striking in these titles is the use of words related to intelligence and creative thinking: inventive, Creative, Genius cheaters, etc. The question we should pose then is "if these cheaters are creative and genius, why do they cheat?"

Actually, cheating during in-class exams involves the use of a variety of tactics. Some are known and others are unknown. According to Phillip C. (2006), in order to cheat examinees use incredible original methods: 


\subsection{Semiotic methods}

A method of cheating that was successful on multiple-choice tests for a while was using signs. For example, a student would watch a student and he or she would signal the other the answer by touching the nose for $A$, touching the chin for $B$, the ear for $C$, and finally touching the top of the head for answer D.

Another plan was to cheat on the exam through silent communication. The way students decided to do this was to give each object on their desk a certain letter meaning. A would be a pencil, B would be a pen, C would be a calculator, and D would be the actual test. When either one of the students did not know the answer to one of the questions she/he would knock the number of the question out lightly on the desk and wait for the other to pick up the object with the letter of the right answer assigned to it.

\subsection{Distracting the Professor}

Distraction is a frequent cheating method student often use in class. One of the students would go to the front and distract the teacher, while the others would get the notes out of their schoolbags or pockets.

\subsection{Creative Smuggling}

Creative smuggling refers to the innovative and illicit means that students use to import unauthorised notes to the examination site. In this section Phillip C. (2006) classifies the innovative smuggling techniques into four thematic categories: 1) body parts 2) articles of clothing 3) technological gizmos 4) ordinary objects.

\subsection{Body Parts}

A student explains through the following narrative:

"Instead of writing the answers in my hand, I would write them on the side of my fingers. If I were asked to present my hands for inspection, there would be no visible evidence of the crime. When the teacher would scan for cheating students, I would put my hand on my forehead "in frustration" and read the answers from between my fingers."

Another common technique was, writing words on the hand and arms. That way it will not be so obvious that one is cheating.

There is, however, a way to cheat that precludes a proctor (invigilate) from taking action against the cheaters. Consider the following narrative:

"It was a long skirt that came down to my ankles with a slit on both sides. Before every test, I would write all the answers on my thigh. When I stood up you could not see because that slit was not that high, but it was high enough when I sat down. When I sat down to take my test, my skirt came up a little. I then crossed my legs, and I could see all the answers that I had written on my leg."

This female student uses her body as an unauthorised cheat sheet, but instead of writing the answers on her hands and arms, she writes them on her legs. The obvious benefit of this method is that it utilises a body part that is unlikely to generate suspicion. Teachers do not normally expect students to write things in sexually suggestive places.

\subsection{Articles of Clothing}

Students regularly admitted taping crib notes onto articles of clothing on the day of the exam. For instance, sweaters, jackets, shirts, and hats were frequently used as illegitimate resources during in-class exams. Consider the following narrative:

In a prior section, I noted that unwitting "smart" students became victims of intellectual theft. To this end, hats provide a literal cover for cheaters whose eyes cannot stay on their own papers; they provide a "perfect angle" for peeking at a neighbour's answers, as this example demonstrates.

Consider another common garb that is used as a way to cheat:

I would tape a cheat sheet upside down on the inside bottom of my shirt. While taking the test I could turn the bottom of my shirt up and get the formula, answer, etc.

\subsection{Technological Gizmos}

Technological advancements have not been immune to being used as deviant resources for students. Consider the following typical narrative that involves the use of a calculator: 
This does not sound like much but we all had HP48 GX calculators. The brilliant thing about these calculators is that they can send information back and forth using infrared light. We never got caught but now in chemistry classes you are not allowed to use these calculators.

\subsection{Ordinary Objects}

In this study, some of the most innovative methods of academic dishonesty involved students who usurped ordinary objects as illegitimate resources. For instance, one student related that he had a friend who wrote the cheat sheet for a chemistry exam in the corner of the frame of his glasses, and peeked at it during the exam, a tactic that is difficult to envision, but not impossible to undertake. Consider the following narrative of a student who cheats by using a rubber band:

"Basically, the night before the test, you can take the rubber band, preferably a thicker one, and stretch it. While stretched, write the answers on the rubber band as small as you can see from about a foot away. Write the answers as close together as you can. When the rubber band is unstretched it will just appear to be colored solid black, but stretched it will reveal the answers. I have not met a teacher that was suspicious of a rubber band".

"Another highly creative method of cheating involves using an ordinary academic accoutrement as a resource":

"I noticed that someone was preparing a cheat sheet. I asked myself what he is doing. He wrote his answers on two small pieces of paper with very small print. The thing that was amazing was how he hid it. He has one of those Bic pens. You know the ones you can see through. Well what he did is he took off the cap of the pen and actually put the cheat sheet in the pen".

The value of using such ordinary academic tools in innovative ways is that the possibility of suspicious attention is diminished. While cheating has been conceptualised as being related to social and environmental factors, this study demonstrates that students tailor their illegitimate methods to adapt to their personal, social, and situational contexts.

\subsection{Research Questions}

In order to confirm our claim that justifies cheating on exams behavior, the following specific research questions were addressed:

1. Is cheating on exams a reasonable and justifiable behavior?

2. What are the main motivations behind cheating on exams?

3. What are the factors that influence this so-called dishonest academic behavior?

4. How does exam anxiety provoke cheating on exams?

5. What, if anything, should educators do to prevent it?

\section{Methodology}

The study was conducted by formulating a survey consisting of twelve multiple-choice items pertaining to academic cheating (see appendix). The purpose of these questions was to find out whether cheating is more common on examinations in the English language department as well as to find out the main motivations behind this so-called academically dishonest behaviour. The study stressed confidentiality and the student's anonymity in order to increase students' participation and obtain reliable responses.

The survey was randomly distributed to second-year students in the department of English, during class time. This manner of distribution was an attempt to ensure the participation of most of the students. Out of the 120 surveys distributed, 100 were returned. By combining each student's individual results, we could determine the factors that motivate students to cheat, and student's involvement in cheating. Finally, the results were tabulated as percentages and were displayed in two graphs: the first one displays the most common factors that motivated students to cheat on exams, and the second one shows student's involvement in cheating behaviour.

\section{Results and Discussion}

Following the collection of data and as far as the students' involvement in cheating on exams is concerned (table 1) it was found that $85 \%$ of the 100 students surveyed had personally engaged in cheating. Another very high number, $76 \%$, expressed their readiness and willingness to cheat on exams whenever possible. The percentages could be higher because there are students for one reason or another refuse to acknowledge they are cheaters. 
Table 1. Involvement in Cheating on Exams

\begin{tabular}{|l|c|}
\hline Involvement in Cheating on Exams & Percentages \\
\hline Q1. Have you ever cheated on exams? & Yes: 85\% \\
\hline $\begin{array}{l}\text { Q2. If the teacher leaves the exam hall for one reason or } \\
\text { another and you notice that students start cheating, will you } \\
\text { do the same? }\end{array}$ & Yes: \\
\hline
\end{tabular}

Figure 1, shows clearly how close is the convergence of the percentages between students' willingness to cheat on exams and their past involvement in cheating.

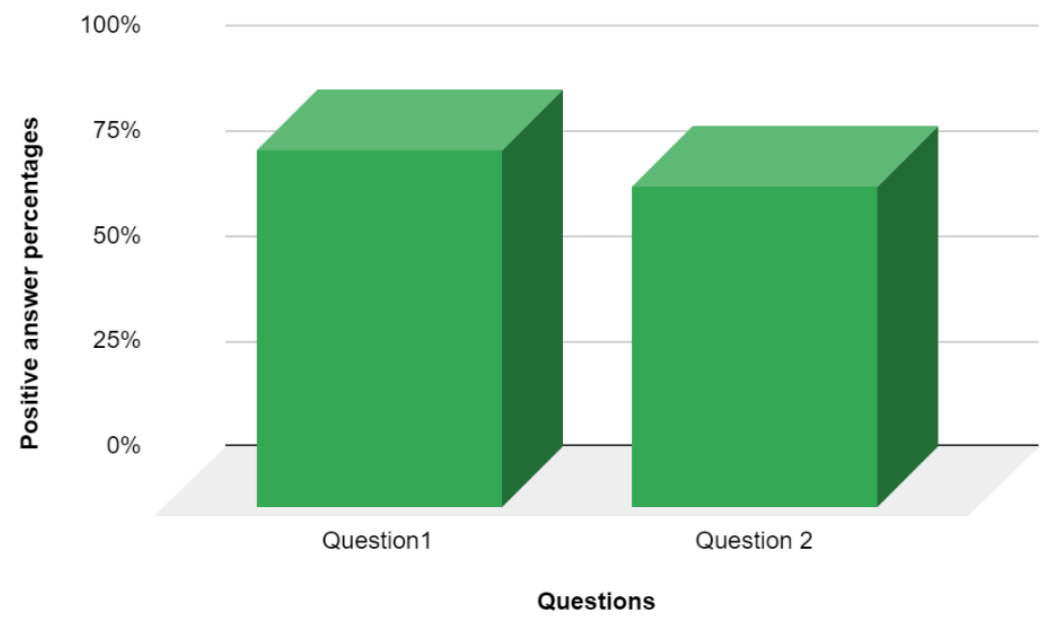

Figure 1. Involvement in Cheating on Exams

As for the factors that motivated students to cheat (Table 2), analysis yielded the following results:

\section{Table 1. Motivating factors}

\begin{tabular}{|l|c|}
\hline Motivating factors & Percentages \\
\hline a. Low instructor vigilance. & $17 \%$ \\
\hline b. Exams focus on memory rather than comprehension & $\mathbf{9 0 \%}$ \\
\hline c. Academic overload & $85 \%$ \\
\hline d. Narrowly spaced exam seating & $14 \%$ \\
\hline e. Lack of self-confidence that they can pass & $\mathbf{7 2 \%}$ \\
\hline f. Students are not prepared for the examination & $\mathbf{6 4 \%}$ \\
\hline g. Students like cheating & $\mathbf{2 8 \%}$ \\
\hline h. Students believe everyone cheats & $48 \%$ \\
\hline
\end{tabular}


We can notice that most of the students, $90 \%$, resort to cheating because of the content of the exams, which focuses on memory rather than comprehension. Another high percentage, $85 \%$, refers to the academic overload that actually makes it too difficult for students to revise the whole stuff and assimilate it. The third important percentage, $72 \%$, relates to the lack of self-confidence that they would pass the exam. This last item needs investigation for we know very little about students' lack of confidence in our context. Is it because of the environment, teachers, students' personalities or something else?

The lowest percentages as shown in Figure 2 are not to be ignored. They mean a lot to the administration and testing services. The low instructor's vigilance (a) with $17 \%$ and the narrowly spaced exam seating (d)with $14 \%$, do not constitute important cheating motivating factors. The third lowest percentage $(\mathrm{g}) 28 \%$ is the one that deserves much attention. This item shows that there are students who cheat on exams just because they like doing so. We can deduce that cheating for this category of learners is like a disease, or obsession. They cheat just because they cannot stop themselves from doing so. They are like Pyromania people who have a propensity for arson, or Kleptomania individuals who cannot resist urges to steal items. In this respect, psychologists should study this category and investigate its role in the so-called cheating on examinations. This type of cheaters may be the source of all evils, education may encounter.

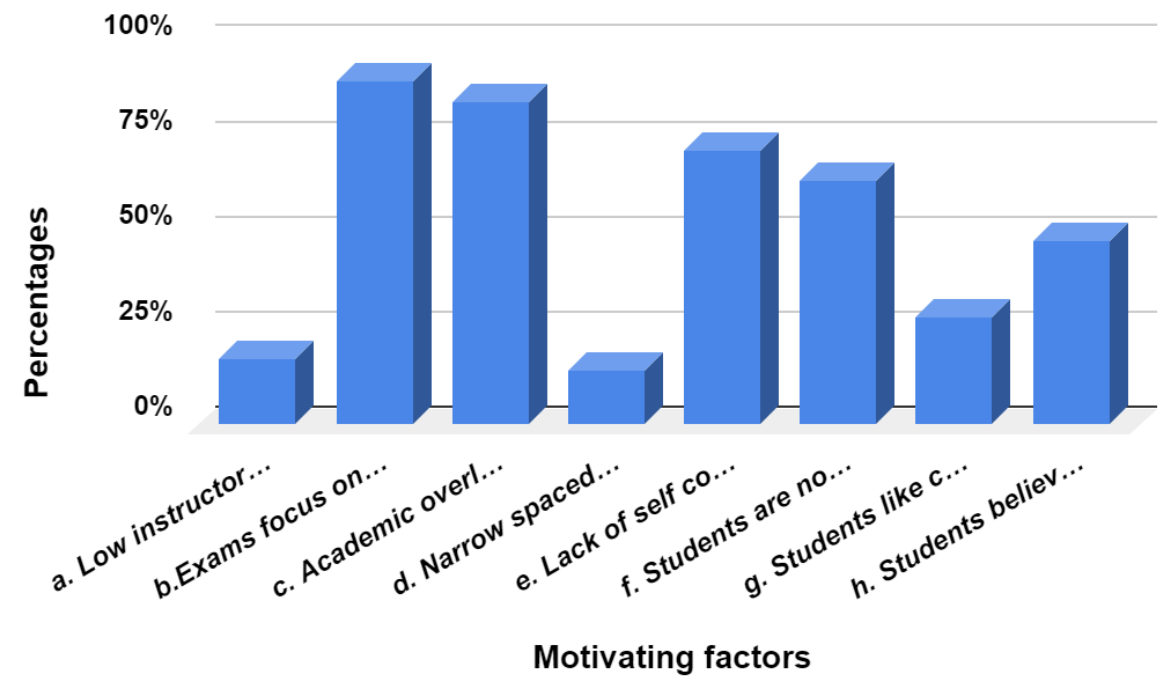

Figure 2: Motivating Factors

\section{Exam Anxiety, Cheating Behavior and Survival Intelligence \\ Exam anxiety}

"While the pressure to perform can act as a motivator, it can also be devastating to individuals who tie their self-worth to the outcome of a test." (ADAA). Indeed, test anxiety has a devastating cumulative effect on the students. They feel helpless and cannot concentrate, and consequently fail to answer the test. Actually, Test anxiety is a true threat to the learner, community and the whole educational system. Its symptoms may say a lot to the teachers, the school administration and testing services. According to the Anxiety and Depression Association of America (ADAA), test symptoms fall into three categories:

\section{- Physical symptoms}

They include headache, nausea, diarrhoea, excessive sweating, shortness of breath, and rapid heartbeat. This test anxiety can lead to intense fear and a panic attack.

\section{- Emotional symptoms}

They include feelings of anger, fear, helplessness and disappointment.

\section{- Behavioral/Cognitive symptoms}

These symptoms of test anxiety include difficulty in concentrating, thinking negatively and comparing oneself to others.

If tests are causing such devastations and destroying the learner, what the hell, are educational authorities waiting to stop this massacre? 
UNESCO claims that the foundation of the United Nations is "building peace in the minds of men and women" and "its work encompasses educational development from pre-school to higher education and beyond. Themes include global citizenship and sustainable development, human rights and gender equality, health and..." (Sam Rose, 2015). Has UNESCO forgotten its role at the international level? Exams are destroying all its values!

Where are human rights associations? Why is the International Court of Justice ignoring the pain of the learner? What has made people believe exams are a normal and sound evaluation operation?

There are old people who commit suicide because of exams. Old people still dream of taking exams, and get nightmares, painful exam nightmares! Their test anxiety pain will stop only when these poor old people die. I am not sure if it does not join them to the grave.

Through this paper in my name and on behalf of all those who have suffered from exams, I submit a complaint to the international court of justice, asking to stop all painful examinations and order institutions to find other civilised ways to evaluate the leaner. Worse, the poor learner, because of thought control, thinks that pain caused by exams is part pf learning and we must accept it.

\section{Survival Intelligence and Cheating}

This intelligence is a combination of verbal and kinaesthetic intelligences. To illustrate this type of intelligences we suggest the following example:

When a person touches a hot stove, screams and withdraws his hand from it without actively thinking about it. The nerves from the body part that touched the stove let the brain know that one should pull away from that hot object otherwise burning oneself. This phenomenon might be similar to the cheating operation. Because of exam-anxiety on the one hand, and when the student's brain finds out that the exam is too difficult, his survival intelligence engages itself and urges the student to resort to any means to overcome both the exam threat and the exam difficulties. This happens mainly when the exam is a cut-off point: one either passes or fails. Among these means, the so-called cheating is the best response.

Unfortunately, though in the $21^{\text {st }}$ Century, education and its assessment system are contradicting the schools objectives, harming human rights, and causing physical and moral pain to millions of students round the world.

The so-called cheating is causing so much harm to education, and we have to think deeply and scientifically about how to solve it, because eradicating it appears to be an impossible mission.

Teachers should remember that cheating in such circumstances is an art and a skill. It is not an easy task. It requires a war like training. Students use it as a response to a threat and they have the right to defend themselves. When teachers remove this threat students will stop cheating.

We might learn a lesson from a student cheater who sent the following letter to his teacher explaining why students are motivated to cheat in exams:

Dear Teachtator,

Yes, I know you are bored to death by academic dishonesty. YOU are complaining about my cheating on exams. YOU are working hard to prevent me from cheating. YOU cannot do itsimply because YOU are the source of cheating. Remember, Cheating is unstoppable. It ends only when YOU end. Check, "Cheat and Teach" are one same word, same letters, and a same meaning.

YOUR examinations are boring and painful. They caused my breakdowns... No one can help. Cheating is my saver, my aspirin, the killer of the pain.

Teacher, YOU should remember that cheating is an art and a skill. It is not an easy task. It is a war job. Students use it as a response to a threat and they have the right to defend themselves. And the threat is YOU. Remove this threat and students will stop cheating.

You covered my eyes with blinkers to keep me looking in the direction YOU are dictating. Cheating rescued me. It taught me how to roll my eyes here and there to see the answer sheets of my schoolmates. My visual style has considerably improved.

YOU trained me how to keep quiet and stick to my seat like the statue of liberty. Cheating broke my handcuffs and freed me. My hands moved everywhere to gather answers. They copied the answers smarter and faster than ever. They broke the record. They are very useful now.

My feet engaged their brain and became practical and helpful. They kicked the chairs, the tables and the legs of my classmates to let them know that I want to cheat and I got what I wanted. 
My poor neck that used to obey the position of my head (I would say YOUR head) won its liberty. Of course, thanks to cheating, it could stretch either ways to search for answers. It has become a true gymnast. I can say that cheating has improved my kinaesthetic intelligence.

Teacher, my ears were allergic to knowledge. They turned sick and deaf whenever they heard YOUR voice. Cheating healed them. It gave them their true role: they became sensitive to the softest whispers and got what schoolmates said. Cheating has developed my auditory learning style.

Teacher, YOU wanted me to learn everything by heart, to store YOUR huge futile stuff in my brain. YOU wanted me to become a parrot. But cheating taught me that the best place to store information is the cell phone and the MP3. I did it, and these devices helped me to cheat on exams and get high scores. Now, technology is my partner. I love it and I can manipulate it efficiently. Before, I was technology illiterate. I hated to use it. Cheating was my ICTs teacher, dear teachtator.

Cheating has turned me Healthy, Smart, and successful. It has solved my problems and has helped me develop my multiple intelligences.

\section{Sincerely yours,}

The Smart Cheater

by the author, Abdelhak Hammoudi

\section{Recommendations/ Suggestions}

Many educational authorities round the world are now targeting schools with detection equipment designed to identify pupils using illegal technological devices to stop cheating. Still, they are unsuccessful: students cheat, beat the records and succeed. They must know that cheating cannot be stopped as far as exams design encourages and motivates students to cheat. Abolishing it starts with providing students with fair exams that offer a variety of questions that appeal to the various intelligences that exist in the average classroom. Then, all the students will have exercises that appeal to them based on their multiple intelligences. When they feel they are likely to be successful in these activities, they do not think of cheating at all. On the contrary, the feeling of success enhances additional learning.

Hence, educators should design tests that do not put much emphasis on rote learning. Instead, they should emphasise higherorder thinking that encourages students to analyse, synthesise and create.

Traditional testing methods are "inherently biased in favor of students with strong linguistic and mathematical skills and do not reflect the diversity of intelligences in the classroom".

(http://www.teachervision.fen.com/intelligence/resource/4933.html)

To differentiate between traditional and MI-based assessment we suggest the following information (table 3):

Table 3. Traditional Vs MI-Based Assessment

\begin{tabular}{|c|c|}
\hline Traditional Assessment & MI Based Assessment \\
\hline Mastery of Facts and Contents & Genuine understanding of the process of learning \\
\hline Facts are mastered for a test & Facts are used as tools for solving problems \\
\hline Testing memory & Comprehension and problem solving \\
\hline
\end{tabular}

Thus, teachers should focus on the features of MI-based assessment (table above) whenever designing a test. They should also remember that exams based on $\mathrm{Ml}$ are closely related to authentic assessment. They should link classwork to authentic experiences. According to teachervision (2012) Ml-based assessment offers efficient tips to design a fair assessment:

- Emphasize ongoing assessment and progress.

- Introduce assessment to your students as a regular part of classroom life.

- Make assessment a part of the learning process, not a stressful, intimidating "event."

- $\quad$ Try to use instruments, tools, and procedures that embrace some, if not all, of the multiple intelligences.

- Use a wide range of assessment tools to measure students' skills and abilities.

Furthermore, to create efficient assessment strategies, educators should familiarize themselves with students' multiple intelligences. Knowing these intelligences can help teachers build tests accordingly and successfully. They can help you choose approaches that will reach them most effectively. Here are some very important strategies that can make assessment fair and intelligent: (teachervision 2012) 


\section{Linguistic}

- Ask students to write in a journal regularly.

- $\quad$ Give oral exams and/or essay tests.

- $\quad$ Emphasise creative writing - have students write poems, plays, and stories.

\section{Logical/Mathematical}

- Have students complete logic problems and games.

\section{Bodily/Kinaesthetic}

- $\quad$ Challenge students to write and perform plays.

- Have students build models or use other hands-on techniques to show what they learned.

\section{Visual/Spatial}

- Invite students to create collages, murals, and posters.

- Encourage students to illustrate their ideas using maps, charts, and graphs.

- Help students use school equipment to make a video or slide show.

\section{Interpersonal}

- $\quad$ Stage a classroom debate.

- Have students work collaboratively to brainstorm and prepare a project.

Intrapersonal

- Ask students to identify their own academic strengths and weaknesses.

Musical

- Have students think of personal goals and give progress reports.

- Challenge students to identify and explain patterns in music or poetry.

- Ask students to write new lyrics to familiar melodies or to compose a new song.

\section{Naturalist.}

- Invite students to lead classmates on a nature walk to point out interesting plants and animals they found during independent study.

- Ask students to keep environmental journals and to share their observations

\section{Conclusion}

Cheating on exams has become more popular all over the world. It has become a big problem that educators have to face to save the school from corruption and destruction. Hence, the main aim of this study was to demonstrate to educators that cheating on exams is most of the time a justifiable and smart behaviour. To support this assumption, the study investigated (a) the reasons that often push students to resort to cheating and (b) the role of exam anxiety in engaging students' survival intelligence to respond to examinations threat with whatever the means. The results, based on a sample of one 100 students from the English language department indicate that $90 \%$ of the students think that the way the examinations are designed constitutes the main cause of cheating: questions test memory rather than comprehension. Teachers themselves trigger cheating on exams because the content of their exams does not take into account students' Multiple Intelligences, and preferred channels of learning. Consequently, students' survival intelligence, feeling a threat causing exam anxiety, engages itself and automatically sets the learner to cheat 'without actively thinking about it.'

Cheating as it occurs today, is a problem we will continue to face. It seems to undermine integrity and can lead to weak life performance. Actually, it is a phenomenon triggered by educational systems round the world. Educational testing services should remember that students are not born to cheat. They are pushed to cheat because of the way teachers design tests. Tests are unfair and neglect students' learning styles. Hence, researchers are urged to find a better way to evaluate students by designing smart exams that take into account students' preferred channels of learning. In our case, we believe implementing multiple intelligences assessment strategies may solve the problem and ensure better student performance. 


\section{References}

[1] Academic Integrity (2018). Administrative Sanctioning Guidelines". Retrieved March7, 2020, from https://academicintegrity.ucsd.edu/process/consequences/sanctioning-guidelines.html

[2] ADAA Test Anxiety. Retrieved July 1st, 2020, from https://adaa.org/living-with-anxiety/children/test-anxiety

[3] CNN investigation (2012). Retrieved May 13, 2020, fromhttp://cnn.com/2012/01/13/health/prescription-for-cheating/index.html\#

[4] College of Earth and Mineral Sciences (EMS). (2002), Academic integrity. Precedent tables. Penn State. Retrieved September 10, 2020, fromhttp://www.ems.psu.edu/students/integrity/tables.html

[5] Dorff, V. (2012), Today's kids view cheating as part of the path to success". Retrieved May 13, 2020, from http://www.allvoices.com/news/12633098-victor-dorff-todays-kids-view-cheating-as-part-of-the-path-to-success

[6] Eberly Center. Carnegie Mellon University. Retrieved April 7, 2020, from https://www.cmu.edu/teaching/solveproblem/stratcheating/index.htm

[7] Graham, M. A., et al. (1994). Cheating at small colleges: An examination of student and faculty attitudes and behaviors", Journal of College Student Development

[8] Independent. (2012). 45,000 caught cheating at Britain's universities". Retrieved April 24, 2019, from http://www.independent.co.uk/news/education/education-news/45000-caught- cheating-at-britains-universities-7555109.html

[9] Lang, J. M. (2013). Cheating lessons: Learning from academic dishonesty. Harvard, MA: Harvard University Press.

[10] Livosky, M., \&Maline, M. B. (1993), Views of cheating among college students and faculty. Psychology in the Schools

[11] Phillip C. H. Shon (2006). How College Students Cheat On In-Class Examinations: Creativity, Strain, and Techniques of Innovation". Ann Arbor, MI: M Publishing, University of Michigan Library

[12] Sam, R. (2015). Building Peace in the Mind of Men and Women. Retrieved June 10, 2020, from https://worldheritageuk.org/2015/11/16/building-peace-in-the-minds-of-men-and- women/

[13] Teachervision. Using Multiple Intelligences in Testing and Assessment". Retrieved June 13, 2020, from http://www.teachervision.fen.com/intelligence/resource/4933.html 